\title{
Functional conservation of Pax6 regulatory elements in humans and mice demonstrated with a novel transgenic reporter mouse David A Tyas' ${ }^{1}$, T Ian Simpson ${ }^{1}$, Catherine B Carr ${ }^{1}$, Dirk A Kleinjan², Veronica van Heyningen ${ }^{2}$, John O Mason ${ }^{1}$ and David J Price*1
}

Address: ${ }^{1}$ Genes and Development Group, Centres for Integrative Physiology and Neuroscience Research, University of Edinburgh, Hugh Robson Building, George Square, Edinburgh EH8 9XD, UK and 2MRC Human Genetics Unit, Western General Hospital, Edinburgh EH4 2XU, UK

Email: David A Tyas - tyas_d@hotmail.com; T Ian Simpson - ian.simpson@ed.ac.uk; Catherine B Carr - c.b.carr@sms.ed.ac.uk; Dirk A Kleinjan - Dirk-Jan.Kleinjan@hgu.mrc.ac.uk; Veronica van Heyningen - veronica.vanheyningen@hgu.mrc.ac.uk; John O Mason - John.Mason@ed.ac.uk; David J Price* - David.Price@ed.ac.uk

* Corresponding author

\section{Published: 04 May 2006}

BMC Developmental Biology2006, 6:21 doi:|0.1|86/|47|-2|3X-6-2|
Received: 08 February 2006

Accepted: 04 May 2006

This article is available from: http://www.biomedcentral.com/I47I-2I3X/6/2I

(C) 2006Tyas et al; licensee BioMed Central Ltd.

This is an Open Access article distributed under the terms of the Creative Commons Attribution License (http://creativecommons.org/licenses/by/2.0), which permits unrestricted use, distribution, and reproduction in any medium, provided the original work is properly cited.

\begin{abstract}
Background: The Pax6 transcription factor is expressed during development in the eyes and in specific CNS regions, where it is essential for normal cell proliferation and differentiation. Mice lacking one or both copies of the Pax6 gene model closely humans with loss-of-function mutations in the PAX6 locus. The sequence of the Pax6/PAX6 protein is identical in mice and humans and previous studies have shown structural conservation of the gene's regulatory regions.

Results: We generated a transgenic mouse expressing green fluorescent protein (GFP) and neomycin resistance under the control of the entire complement of human PAX6 regulatory elements using a modified yeast artificial chromosome (YAC). Expression of GFP was studied in embryos from 9.5 days on and was confined to cells known to express Pax6. GFP expression was sufficiently strong that expressing cells could be distinguished from non-expressing cells using flow cytometry.

Conclusion: This work demonstrates the functional conservation of the regulatory elements controlling Pax6/PAX6 expression in mice and humans. The transgene provides an excellent tool for studying the functions of different Pax6/PAX6 regulatory elements in controlling Pax6 expression in animals that are otherwise normal. It will allow the analysis and isolation of cells in which Pax6 is activated, irrespective of the status of the endogenous locus.
\end{abstract}

\section{Background}

Pax6 is a transcription factor containing an N-terminal DNA binding domain, a paired domain, separated by a glycine-rich linker sequence from a second DNA binding domain, a homeodomain, and a C-terminal proline-serine-threonine-rich transregulatory domain. It is highly conserved in very diverse species. In mammals, it is expressed during development in the eye, in specific regions of the CNS, in the nasal placodes and olfactory epithelium and in the pancreas [1-3]. Haploinsufficiency for Pax6 function $\left(\mathrm{PaxG}^{+/-}\right)$in the mouse results in the Small eye (Sey) phenotype [4]. Homozygotes (Pax6-\%) die perinatally with no eyes and many brain abnormalities [314]. PAX6 haploinsufficiency also causes eye and brain defects in humans $[15,16]$. 


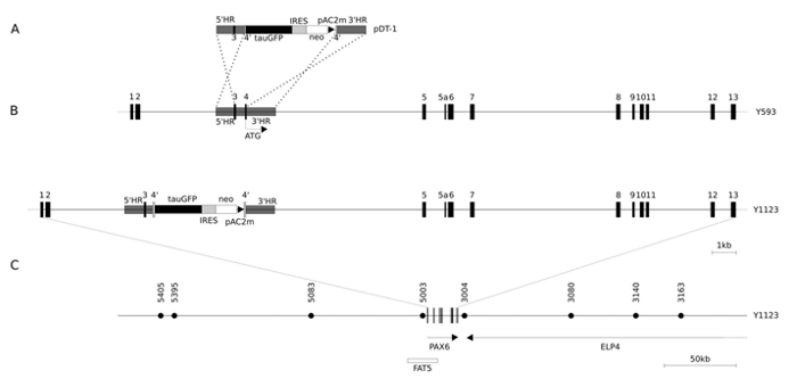

Figure I

Generation of YAC Y I I 23 and DTy54 transgenic mice. (A) Construct pDT-I contained sequences expressing tau-GFP and conferring neomycin (neo) resistance, separated by an internal ribosomal entry site (IRES), terminated with polyadenylation and C2MAZ (PAC2m) sequences and flanked by 5 ' and 3 ' homology regions (5'HR and 3 'HR). (B-C) Homologous recombination resulted in the introduction of this construct at the translation initiation site (ATG) in exon 4 of the human PAX6 locus, contained in YAC Y593 [17], to produce YAC YII23. Successful integration of the modified PAX6 locus into the mouse genome was checked on Southern blots using cosmid FAT5 [17] as a probe and by PCR using primers indicated by filled circles in $C$ (sequences in Methods). The modification was designed such that the tauGFP and neomycin resistance cassettes would be controlled by the gene's regulatory elements and would prevent the production of $\mathrm{PAX} 6$ protein from the translational start site in exon 4. The position of the ELP4 gene is marked.

Normal development requires not only that Pax6 be present in certain cells at certain times but also that it be present in the correct amounts. Schedl et al. [17] showed that severe eye abnormalities are caused not only by under-expression but also by over-expression of Pax6 in mice. Bishop et al. $[18,19]$ and Muzio et al. [20] provided evidence that graded expression of Pax 6 across the developing neocortex of mice is essential for the correct specification of its major areas. Such findings imply that Pax6 expression is tightly regulated and that different levels are maintained in different regions as they grow.

Work on humans has indicated that the PAX6 regulatory elements extend over more than two hundred kilobases [21-24]. The locus is highly conserved, both in the coding regions (human and mouse proteins are identical) and also in the non-coding regions, where similar long-range control elements have been identified in mouse and Fugu by genomic sequence comparisons and DNaseI hypersen- sitivity analysis [24-26]. A YAC (named Y593) containing $420 \mathrm{~kb}$ of the human coding sequence and flanking regions, extending beyond its putative regulatory elements, rescues the mouse Pax6-- phenotype, whereas a YAC containing $110 \mathrm{~kb}$ less flanking sequence does not $[17,24]$. In the work described here, we modified Y593 by introducing tau-GFP and neomycin resistance cassettes so that they would be controlled by the gene's regulatory elements and would prevent the production of PAX6 protein from the translational start site in exon 4 (Fig. 1). This new YAC (called Y1123) was then used to generate transgenic mice.

\section{Results}

\section{Initial characterization of transgenic mice}

Y593 was successfully modified as illustrated in Fig. 1 and as described in Methods to generate Y1123. This YAC was used to generate transgenic mice. Three fertile transgenic founders, named DTy22, DTy42 and DTy54, were identified. They all appeared phenotypically normal and successfully transmitted a tau-GFP-expressing Y1123 transgene to their offspring. PCR with primers marked in Fig. 1 (sequences in Methods) was used to examine the minimum extent of incorporation of Y1123: the results indicated that only DTy54 had incorporated at least the majority of Y1123, whereas DTy22 and DTy42 had incorporated truncated versions. Neither DTy22 nor DTy42 recapitulated the full expression pattern of Pax6. It was possible to identify DTy54 and DTy42 transgenic mice using a hand-held torch emitting blue light, of the wavelength required to excite GFP, and an appropriate filter, as described in [27]. This revealed GFP expression in the eyes of living DTy54 and DTy42 mice; the eyes of DTy22 mice did not express GFP. DTy42 mice expressed GFP only in the eyes. Using DTy54 mice, Y1123 was crossed into embryos that were either $\mathrm{PaxG}^{+/-}$or $\mathrm{PaxG}^{-} \%$. Unlike the unmodified YAC Y593 [17], Y1123 produced no rescue of either the eye or brain defects in these mutants, confirming its predicted lack of function.

Quantitative PCR (qPCR) was used to compare relative fluorescence intensities following amplification with primers specific for human PAXG and mouse Pax 6 or for human PAX6 and mouse Pax3. Intensities following amplification for mouse Pax 6 and Pax 3 were halved (since there are two copies of each in the mouse genome). The ratios between the intensities from PAXG and half the intensities from Pax6 and Pax3 are shown in Table 1. We conclude that one copy of Y1123 (or a part of Y1123 in DTy22 and DTy42) had integrated into the genome of each founder. Fluorescent in situ hybridization (FISH) using the entire FAT5 cosmid (Fig. 1) as a probe [17] on blood smears from DTy54 showed a single signal per cell, confirming that there were not multiple sites of integration. DTy22 and DTy42 were not studied further here. 
Table I: Numbers of copies of integrated transgenes This was estimated from the average of the ratios between fluorescence intensities using primers for human PAX6 and $0.5 \times$ the fluorescence intensities using primers for mouse Pax3 or Pax6 in qPCR reactions on a constant amount of DNA from each of a series of embryos. Each qPCR reaction was repeated three times on each animal.

\begin{tabular}{cccc}
\hline Lines & \multicolumn{2}{c}{ Average ratios $( \pm S D)$} & Numbers of animals \\
\cline { 2 - 3 } & PAX6/0.5 $\times$ Pax3 & PAX6/0.5 $\times$ Pax6 & 7 \\
DTy54 & $0.8 \pm 0.2$ & $0.9 \pm 0.4$ & 6 \\
DTy22 & $1.3 \pm 0.5$ & $1.0 \pm 0.5$ & 8 \\
DTy42 & $1.4 \pm 0.5$ & $1.2 \pm 0.5$ & 7 \\
\hline
\end{tabular}

\section{Expression of tau-GFP in DTy54 mice}

To test whether the tau-GFP expression in DTy54 mice was consistent with the established Pax6 expression pattern, embryos were collected at embryonic day (E) 9.5, $10.5,12.5,14.5$ and 16.5 and eyes were taken from adults. Expression of tau-GFP was seen in the eyes at all ages; examples are shown at E9.5 (Fig. 2A,B), E10.5 (Fig. 2D) and E14.5 (Fig. 3A,B). Expression was present in the retina and lens, as expected, and allowed cellular processes to be visualised due to cytoplasmic labelling by tau-GFP. Particularly striking was label in the axonal projections of retinal ganglion cells, which could be seen in the optic nerve (Fig. 3B-D) and followed through the optic chiasm into the optic tract (Fig. 3E). Elsewhere, tau-GFP expression was confined to regions known to express Pax6 $[1,6,7,9,10]$. As expected, expression at E9.5-10.5 was in the forebrain (in the telencephalic and diencephalic vesicles), with a sharp posterior boundary of expression at the diencephalic/mesencephalic boundary $[7,10]$, and also in the hindbrain and spinal cord (Fig. 2). Figure 3F shows a parasagittal section through the brain at E14.5: expression was in the cerebral cortex, prethalamus (also known as the ventral thalamus), pretectum, the basal plate in the region of the pons [28] and in the cerebellar primordium [11]. The intensity of label in the cerebral cortex was graded from high rostrally to low caudally (Fig. $3 \mathrm{~F}$ ), in line with the known gradient of expression of Pax6, which is shown using an anti-Pax6 antibody in Fig. $3 M[18,20]$. Similar to earlier ages, there was a sharp posterior boundary of expression at the border between pretectum and midbrain (arrow in Fig. 3F) $[7,10]$. In coronal sections, expression of tau-GFP was seen in the pineal gland (Fig. 3G) and nearby in the posterior commissure (not shown), which are also sites of Pax6 expression [14]. There was expression in the prethalamus (Fig. $3 \mathrm{H}$ ) in a pattern similar to that shown with an anti-Pax6 antibody (Fig. 3L). In the pallium (Fig. 3H), there was a boundary of expression at the border between the pallium and subpallium, in agreement with the known boundary of Pax6 expression (Fig. $3 \mathrm{~K})[7,10]$. Label was seen running ventrally to the amygdaloid region (Fig. 3H), mirroring the known expression of Pax6 in this area $[9,29]$. In the cerebral cortex, tau-GFP was seen in the radial processes of cells located on the ven- tricular side of the cortical wall (Fig. 3I); again, this was anticipated since Pax6 is known to be expressed in radial glial cells [30]. There was expression in the olfactory epithelium (Fig. 3J) [1,2].

Immunhistochemistry with anti-Pax6 and anti-GFP antibodies confirmed the presence of GFP in Pax6-expressing regions. An example of co-localization at E12.5 is shown in Fig. 4: Pax6 is expressed on the pallial side of the pallial/subpallial border (Fig. 4A), as is tau-GFP (Fig. 4B,C). Overall, we concluded that the patterns of label with tauGFP are exactly as anticipated on the basis of the known expression of Pax 6 and that regional differences in the intensity of label in the cerebral cortex reflect known differences in the level of expression of Pax6.

\section{Analysis of DTy54 brains with flow cytometry}

One of the potential uses of this transgenic mouse is to allow the isolation of Pax6-expressing cells. We demonstrated that this is possible using flow cytometry on dissociated cells from the brains of E14.5 embryos. The telencephalic vesicles were removed and each was cut into dorsal, lateral and ventral components. Data are shown in Fig. 5. Analysis of non-transgenic embryos provided frequency distributions of background fluorescence intensity (Fig. 5A). A gate was set to cover intensities above the upper limit of the fluorescence seen in these controls, on the basis that cells falling within this gate in transgenic embryos (Fig. 5B-D) were certain to be expressing tauGFP. In samples from dorsal telencephalon of DTy54 embryos (Fig. 5B), a large proportion of cells had fluorescence levels within the gate. There were also large numbers of cells whose fluorescence intensities were not within the gate but were higher than the average intensity in non-transgenic controls. It is likely that these are cells expressing GFP at lower levels; for example, many may be in the process of down-regulating the transgene as they differentiate, which is the pattern of expression of Pax6 $[1,6,12]$. A similar picture was seen in samples from the lateral and ventral telencephalon (Fig. 5C,D). The average fluorescence intensity of cells within the gate was higher in the lateral telencephalon than in the dorsal telencephalon (peak shifted to the right in Fig. 5C compared to 


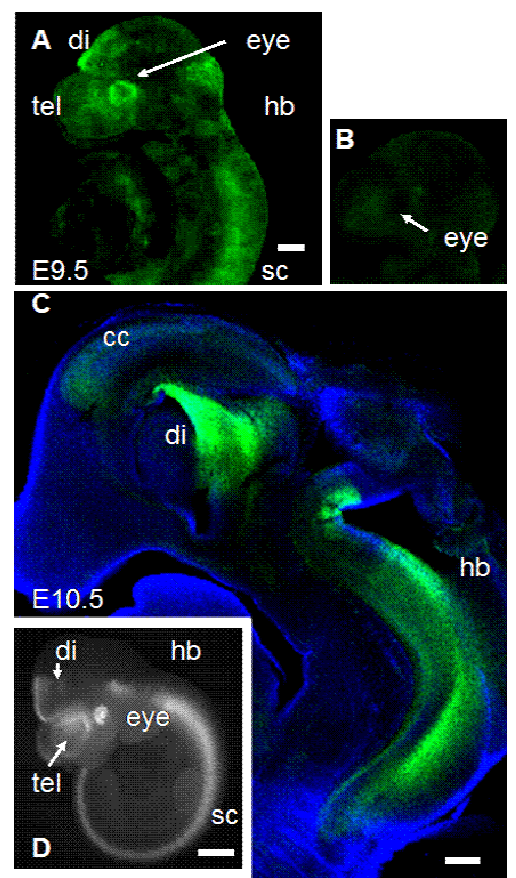

\section{Figure 2}

Expression of tau-GFP in DTy54 transgenic mice at

E9.5-10.5. (A) Whole E9.5 DTy54 embryo showing expression in the eye, forebrain (telencephalon, tel, and diencephalon, di), hindbrain (hb) and spinal cord (sc). (B) Whole E9.5 wild-type embryo showing lack of expression. (C) Parasagittal section through an EI0.5 DTy54 embryo showing expression in the cerebral cortex (cc), diencephalon and hindbrain. (D) Whole EI0.5 DTy54 embryo showing expression in the eye, forebrain (telencephalon, tel, and diencephalon, di), hindbrain (hb) and spinal cord (sc). Scale bars: A-C, $200 \mu \mathrm{m}$; D, $500 \mu \mathrm{m}$.

Fig. 5B), which agrees with the brighter fluorescence of cells in this region in sections (Fig. $3 \mathrm{H}$ ). The proportion of cells within the gate was smallest in samples from the ventral telencephalon (Fig. 5D), which agrees with the fact that fewer cells in this region express Pax6 (Fig. 3H).

\section{Discussion}

In DTy54, the modified YAC that had integrated into the mouse genome did not affect the endogenous Pax6 locus, unlike an alternative strategy involving the insertion of a reporter gene into the endogenous locus [3]. The
YAC1123 transgene can be crossed onto mice with any Pax6 status (e.g. Pax6 $6^{+/+}, \operatorname{Pax}^{+/-}, \operatorname{Pax} \%$, $\operatorname{Pax}^{\operatorname{lox} P / l o x P}$ ) to identify and isolate those cells in which Pax 6 is being activated by upstream factors. In addition to generating a useful new tool for understanding the role of $\operatorname{Pax} 6$, our results demonstrate that the elements regulating the human PAX6 gene present in Y1123 and Y593 [17] are necessary and sufficient to recapitulate accurately the expression of Pax6 in mice. This indicates that these elements are not only structurally $[24,25]$ but also functionally highly conserved. In their original study of mice containing human PAX6-expressing YACs, Schedl et al. [17] suggested functional conservation of the regulatory elements controlling the human and mouse genes on the basis that the human locus is able to complement the Sey mutation in mouse. The introduction of PAX6-producing transgenes corrected the eye defects in heterozygotes and rescued homozygotes from perinatal death. It remained unclear, however, how accurately the human regulatory elements reproduce the pattern of endogenous mouse Pax 6 expression. Although Y593 must have caused re-expression of the missing factor in those cells that normally express it, thereby rescuing their abnormal phenotypes, additional ectopic expression from Y593 might have gone undetected. Our current work complements that of Schedl et al. [17] by demonstrating a remarkable conservation of function of the Pax6/PAX6 regulatory elements in the two species.

Recently, Kim and Lauderdale [31] described the generation of a bacterial artificial chromosome (BAC) transgenic reporter mouse containing $160 \mathrm{~kb}$ of mouse genomic DNA from around the mouse Pax 6 gene. Unlike the YAC transgene described here, the BAC transgene did not generate expression in diencephalic and olfactory cells that are known to express Pax6. A likely explanation for this difference is that the shorter BAC transgene is missing some important regulatory elements. Figure 6 compares YAC Y593 (which spans the same genomic interval as its derivative, YAC Y1123) with BAC mBAC293d08 [31]. BAC mBAC293d08 lacks the genomic region between ELP4 exons 4 and 7 that comprises part of the downstream regulatory region (DRR) in the human. LAGAN/ VISTA pairwise alignment identifies five highly conserved regions that could contain regulatory elements responsible for differences in expression between the transgenic reporter mice carrying mBAC293d08 and Y1123 (Fig. 6).

\section{Conclusion}

This work provides further evidence that the Pax6/PAX6 regulatory elements are highly conserved not only structurally but also functionally in mice and humans. Y1123 provides an excellent tool for studying the functions of different Pax6/PAX6 regulatory elements and will allow the analysis and isolation of cells in which Pax6 is activated, irrespective of the status of the endogenous locus. 

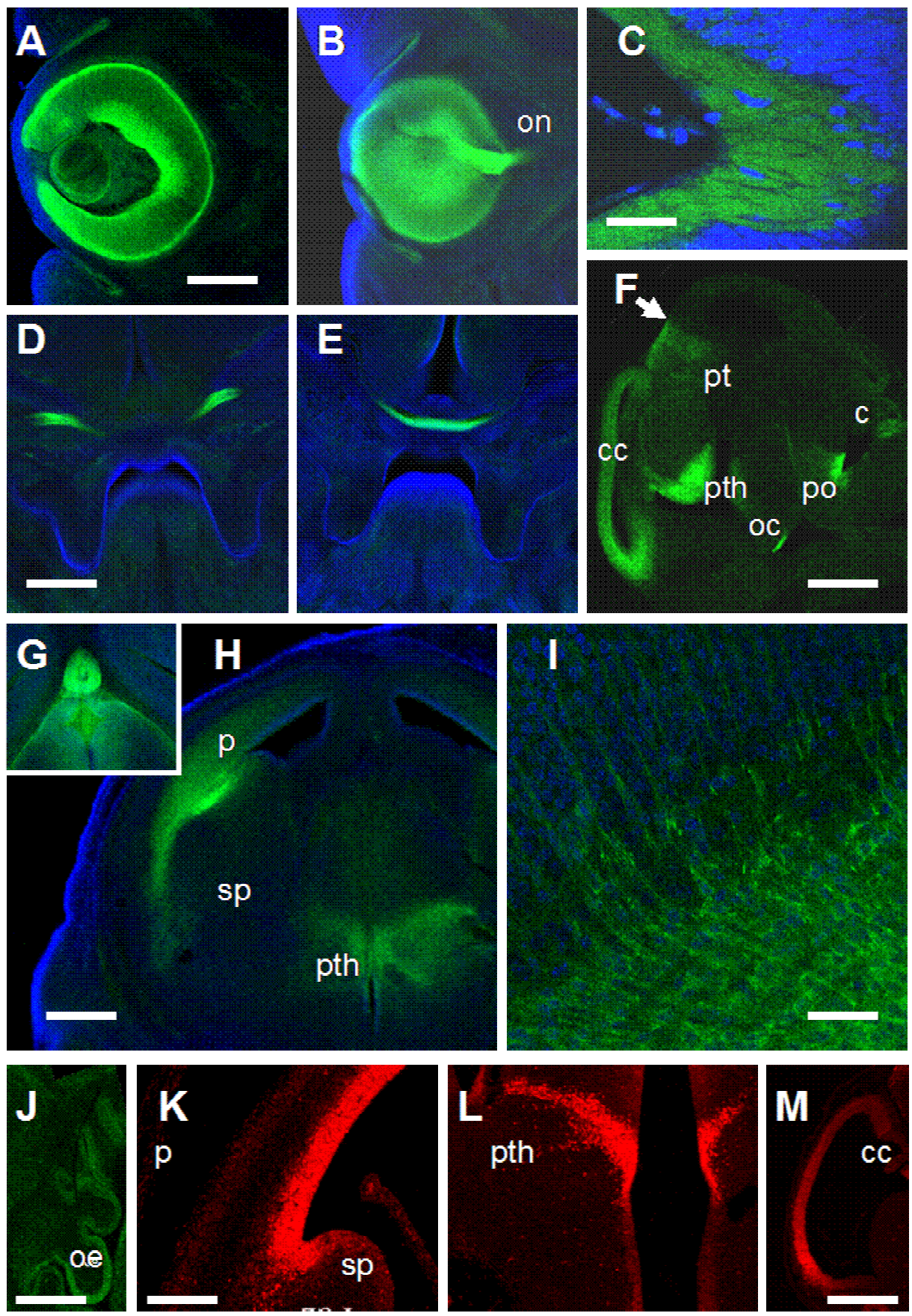

\section{Figure 3}

Expression of tau-GFP in DTy54 transgenic mice at EI4.5. (A-E) Sections showing tau-GFP in the eye and optic tract. The optic nerve (on) contains tau-GFP (B-D). Axons containing tau-GFP are seen emerging from the retina at the optic nerve head (C) and forming the optic chiasm (E). (F) Parasagittal section through the brain at EI4.5 showing tau-GFP in the cerebral cortex (cc), prethalamus (pth), pretectum (pt), optic chiasm (oc), basal plate of the pons (po) and primordial cerebellum (c). Arrow points to the posterior boundary of the pretectum. (G-I) Coronal sections at EI4.5 showing tau-GFP in the brain: (G) the pineal gland, $(H)$ the pallium (P), subpallium (sp) and prethalamus and (I) the cerebral cortex. (J) Section through the olfactory epithelium (oe). (K-M) Expression of Pax6 shown with immunohistochemistry on coronal sections. Scale bars: A,B 200 $\mu \mathrm{m} ; \mathrm{C}, 20 \mu \mathrm{m} ; \mathrm{D}, \mathrm{E}, \mathrm{G}, \mathrm{H}, \mathrm{J}-\mathrm{L}, 300 \mu \mathrm{m} ; \mathrm{F}, \mathrm{M}, 900 \mu \mathrm{m}$; I, $50 \mu \mathrm{m}$. 

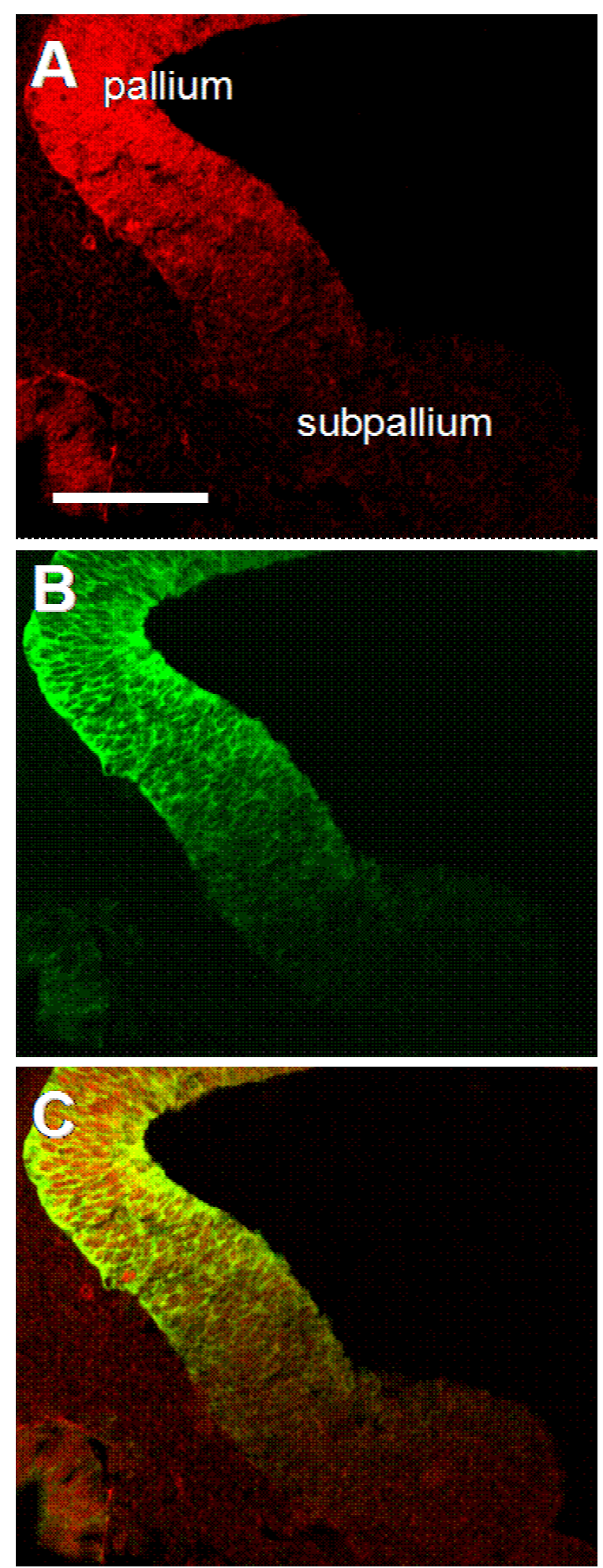

Figure 4

Expression of tau-GFP in DTy54 transgenic mice at E 12.5. Coronal sections through the pallial/subpallial border of EI2.5 embryos stained with antibodies against Pax6 (A) and GFP (B); images are merged in C. Scale bar: $200 \mu \mathrm{m}$. 


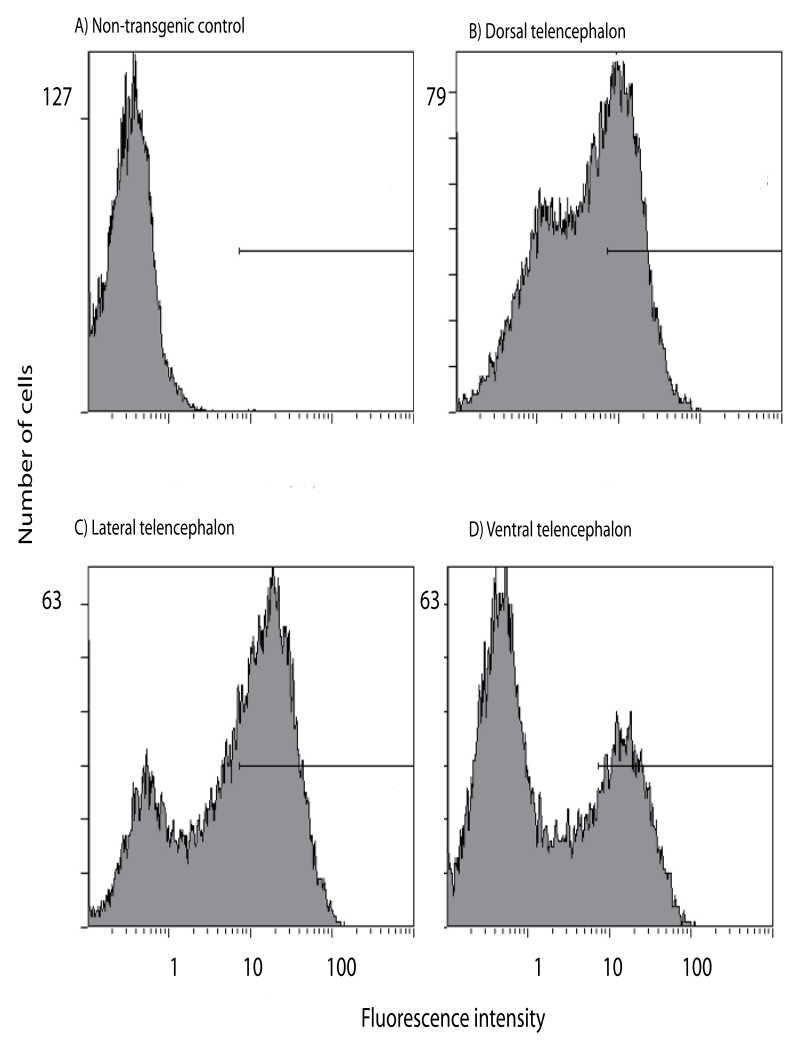

Figure 5

Expression of tau-GFP in DTy54 transgenic mice at E I 4.5 quantified with flow cytometry. Frequency histograms of cell number against GFP fluorescence for samples of cells from $(A)$ the telencephalon of non-transgenic controls and (B-D) the dorsal, lateral and ventral parts of DTy54 embryos.

\section{Methods}

\section{Generation of the DTy54 transgenic mouse}

All work on mice followed current Home Office (UK) regulations stipulated in the Animals (Scientific Procedures) Act 1986. An overview of the strategy is illustrated in Fig. 1 . We inserted a tau-GFP reporter cassette and a neomycin resistance cassette, linked by an internal ribosomal entry site (IRES), in frame into the translation start site in exon 4 of the PAX6 gene in YAC Y593 [17] by homologous recombination using a yeast URA3 selectable marker. The manipulated YAC (named Y1123) was then used to generate transgenic mice.

Integration of YAC Y593 into yeast window strain W3

Before modifying the parental YAC Y593 with the reporter construct, it was introduced into a yeast window strain. This was necessary because Y593 co-migrates with similar sized endogenous yeast chromosomes in pulse field gel electrophoresis, making it difficult to isolate from the endogenous chromosomes. Each window strain contains defined alterations in its karyotype, which provide a large size interval, or window, devoid of endogenous chromosomes [32,33]. Window strain W3 was mated with Y593 using the kar-cross method [34,35]. Y593, in addition to the PAX6 gene locus, contains the genes allowing yeast cells to produce adenine and tryptophan. By removing adenine hemisulfate salt and tryptophan from the growth medium, it was possible to select for yeast colonies expressing these genes and, therefore, containing Y593.

Integration of reporter cassette into Y593 by homologous recombination

Y593 was modified to generate a new YAC (named Y1123) using the plasmid pDT-1 (Fig. 7), which contained the following elements (Figs. 1, 7). (i) Coding sequence for tau-GFP fusion protein; the microtubule binding protein tau would allow the visualisation of the processes of expressing cells [13]. (ii) An IRES followed by an optimised Kozak translation consensus start site (IRESKozak) to allow the translation of two cis genes from a single transcript [36]. (iii) A neomycin resistance (neo) cassette to allow G418-based selection of expressing cells. (iv) A polyadenylation ( $\mathrm{pA}$ ) site to allow polyadenylation of the tau-GFP-IRES-neo mRNA. (v) A C2MAZ site to slow RNA polymerase II [37] and promote transcription termination; the aim was to further reduce the chances of transcription of the entire targeted locus, which might have reduced marker expression through splicing around exon 4 .

Once Y593 had been moved into the window strain it was transformed with the bacterial construct pDT-1 using modified lithium acetate yeast transformation. W3 has a defective URA3 gene and is unable to survive pyrimidine starvation. Since pDT-1 contained the yeast gene URA3 (Fig. 7), any cell harbouring Y593 into which pDT-1 had recombined survived pyrimidine starvation and was selected by the omission of uracil from the growth medium.

Several colonies were picked and screened for the likely presence of a complete pDT-1 using PCR for parts of pDT1 distant from the URA3 gene and with Southern blots. Of 18 clones screened, one showed correct first round recombination. This clone was grown in the presence of 5fluoroorotic acid (5-FOA), which prevents yeast cells containing the URA3 gene from growing and provides selection for removal of the URA3 gene by internal homologous recombination [38,39]. Nine clones were picked from the 5-FOA plate, designated 1121 to 1129 , and Southern blots were done to identify correct clones. One clone (1123) was identified as correct, giving a suc- 
cess rate of about $11 \%$. PCR combined with restriction digests on some of the PCR products was used to confirm that the individual parts of the reporter cassette were present in the clone. The junction between PAXG and tauGFP was checked by sequencing in both directions, confirming that the PAX6 ATG in exon 4 was followed immediately by tauGFP.

\section{Microinjection of Y I I 23 and initial assessment of transgenic mice} Y1123 DNA was isolated for microinjection using alternating contour-clamped homogeneous electric field pulse field gel electrophoresis [40]. Injected one-cell embryos (from crosses of $\mathrm{C} 57 \mathrm{Bl} / 6$ and CBA mice) were either replaced immediately into pseudopregnant female mice or first cultured overnight until two-cell. About 5\% of injected one-cell embryos were born. Subsequent breeding was such that all mice carrying Y1123 studied here were hemizygous for the transgene. Southern blotting with a full-length cDNA probe was used to confirm that the modified PAX6 coding region had integrated. PCR with primers shown in Fig. 1 was used to confirm the extent of incorporation of Y1123. The primer sequences were:

3163F AAGCCATTTTGTTGGTGAGC

\section{R TTCCAGTTATACAGGGGCTGA}

\section{F AAGGTGCCCAGCCTAATTCT}

\section{R TCGTCTCGATCTCCTGACCT}

5003F CAGAGGGAGGACCTCTCAGG

5003R TTTGCCTTTAGGGCTCACTG

3004F CTTCCCTGGCTACCATGTCT

3004R CGGCCCAGTGAATTAGAAAA

3080F TGAAAATGCAAACAGGTTCC

3080R AAGCCGTCAGACCACTTTTG

5083F TGAGAGCTGTGCAGAGCAGA

5083R GAAAGCAAAACCCTGGACAA

5405F GCCATCTGAAAGCTGAGGAG

5405R CCAGCCTACCTTGACATGCT

5395F GACACGCTGGTCACCAAGTA

5395R TTACAGCGGACCCCTCTTC
FISH on blood smears, with cosmid FAT5 as a probe (marked as CFAT5 in Fig. 1) and methods described in Schedl et al. [17], was used to search for possible multiple integration sites. Quantitative PCR (qPCR; QuantiTect SYBR Green PCR Kit, Qiagen) was used to identify the number of copies of Y1123 present in the genome, using three sets of primers, one specific for human PAX6, one specific for mouse Pax 6 and one specific for mouse Pax3. The latter two sets were standards (detecting genes with copy numbers of 2) against which to compare the intensity of the product from Y1123. The three sets of primers were as follows: (i) human PAX6 specific primers (PAX6HumF CCGTGTGCCTCAACCGTA, PAXGHumR CACGGTTTACTGGGTCTGG); (ii) mouse Pax6 specific primers (Pax6MouF CGCAAATACACCTTTGCTCA, Pax6MouR GAGGGTTTCCTGGATCTGG); (iii) mouse Pax3 specific primers (Pax3MouF AAGCAGCGCAGGAGCAGAACC, Pax3Mour CCTCGGTAAGCTTCGCCCTCT). These three sets of primers allowed the amplification of sequences of similar length with similar reaction kinetics. Conditions were such that the fluorescence intensity was related linearly to the amount of starting DNA; once this had been established, $300 \mathrm{ng}$ of DNA was used in each qPCR reaction. By comparing the fluorescence generated with sets two and three against the fluorescence generated when the same amount of DNA was used with set one, the number of PAX 6 gene copies was calculated. Each reaction was repeated three times on each of a series of embryos.

\section{Assessing the transgene's expression}

Pregnant females were killed at various ages by cervical dislocation and embryos were fixed overnight in ice cold $4 \%$ paraformaldehyde and embedded in $4 \%$ low melting point agarose (the day of the vaginal plug was designated E0.5). Vibratome sections were cut at $200 \mu \mathrm{m}$, counterstained with TOPRO3 (Molecular Probes, NL), mounted on glass slides and imaged using a Leica confocal microscope. For immunohistochemistry, tissue was fixed overnight in $4 \%$ paraformaldehyde, transferred to $15 \%$ sucrose, embedded in $7.5 \%$ gelatin/15\% sucrose in phosphate buffered saline and placed in $30 \%$ sucrose overnight. Cryostat sections $(15 \mu \mathrm{m})$ were cut and transferred to $20 \%$ goat serum in phosphate buffered saline containing $0.1 \%$ Triton-X for $30 \mathrm{~min}$ at room temperature. Sections were incubated with mouse anti-Pax6 ascites (1:5000; Developmental Studies Hybridoma Bank) and rabbit anti-GFP antibody (1:10000; Abcam) overnight at $4^{\circ} \mathrm{C}$ and for $1 \mathrm{hr}$ at room temperature the following day. Secondary antibodies were goat anti-mouse and goat antirabbit Alexa fluor 568 and 488 respectively (1:150; Molecular Probes), applied for $1 \mathrm{hr}$ at room temperature.

\section{Flow cytometry}

Telencephalic tissue from E14.5 wild-type and DTy54 embryos were dissociated with papain (Papain Dissocia- 


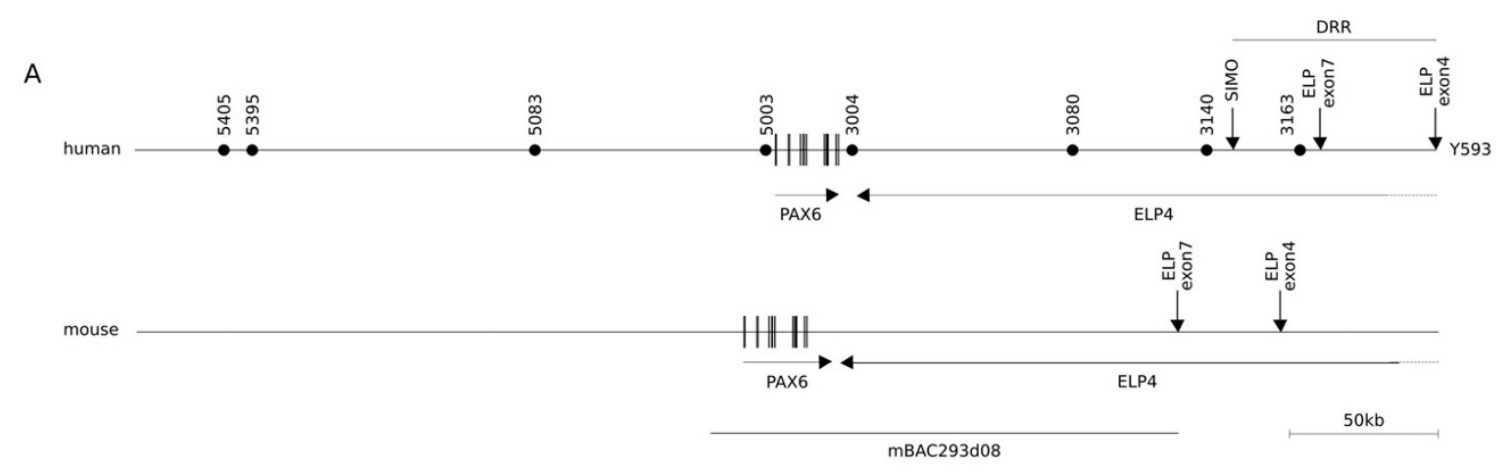

B

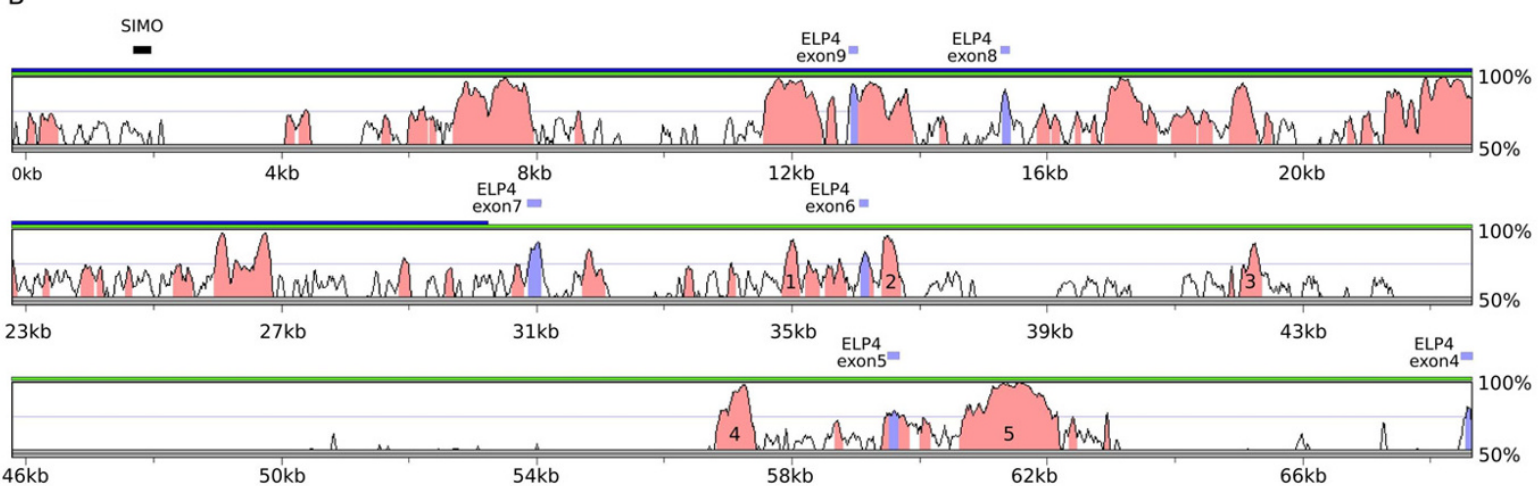

\section{Figure 6}

Genomic comparison of YAC Y593 and BAC mBAC293d08. (A) The PAX6 gene is located centrally in Y593 [17]. The $3^{\prime}$ end of Y593 is marked by exon 4 of the ELP4 gene. YAC Y593 has not been end-sequenced but is known to reside between the STS markers AFM324yh5 20 kb 5' and DI IS4662 I7 kb 3' to the YAC and is approximately $420 \mathrm{~kb}$ in length. The DRR (downstream regulatory region) is defined at the $5^{\prime}$ end by the SIMO breakpoint and at the 3 ' end by ELP4 exon 4 [3 I]. Mouse BAC mBAC293d08 spans the region $12 \mathrm{~kb} 5$ ' to exon 0 of Pax6 through to approximately $0.6 \mathrm{~kb}$ before ELP4 exon7 and is 160 $\mathrm{kb}$ in length [3I]. It therefore lacks the genomic region between ELP4 exons 4 and 7 that comprise part of the DRR region in the human. (B) LAGAN/VISTA pairwise alignment of human and mouse genomic intervals spanning the region from SIMO to ELP4 exon 4 [4I,42]. The 3' extent of mBAC293d08 is shown by the blue bar and of Y593 by the green bar. Regions shaded pink demark regions of $>50 \%$ sequence identity over a window of $100 \mathrm{bp}$. In the 3' region common to $\mathrm{Y} 593$ and $\mathrm{Y}$ I I 23 , but absent from mBAC293d08, rankVISTA analysis identifies five non-coding regions that are evolving more slowly than a modelled neutrally evolving base sequence $(\mathrm{I}: 199 \mathrm{bp}=2.2 \mathrm{e}-03,2: 466 \mathrm{bp}=1.3 \mathrm{e}-07,3: 223 \mathrm{bp} \mathrm{p}=8.3 \mathrm{e}-04,4: 509 \mathrm{bp} \mathrm{p}=1.0 \mathrm{e}-12$ and 5: 1564 bp $p=1.6 e-42)$ [43]. These highly conserved regions could contain regulatory elements responsible for differences in expression between the transgenic reporter mice carrying mBAC293d08 and YII 23.

tion System, Worthington Biochemical). Cells in suspension were analysed on a Beckman-Coulter XL flow cytometer $(10,000-20,000$ cells were analysed per sample).

\section{Abbreviations}

BAC, bacterial artificial chromosome; c, cerebellum; cc, cerebral cortex; di, diencephalon; DRR, downstream regulatory region; E, embryonic day; 5-FOA, 5-fluoroorotic acid; FISH, fluorescent in situ hybridization; GFP, green fluorescent protein; hb, hindbrain; HR, homology region; IRES, internal ribosomal entry site; neo, neomycin resist- 


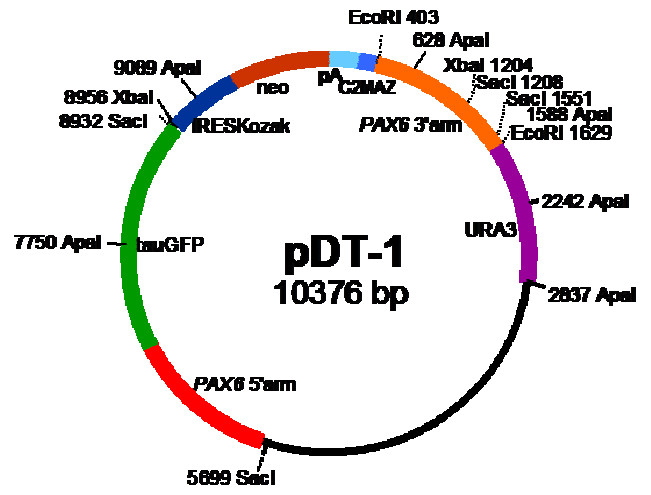

Figure 7

Map of plasmid pDT-I. The components of the construct shown in Fig. IA and the URA3 sequence are marked.

ance; oc, optic chiasm; oe, olfactory epithelium; on, optic nerve; $\mathrm{p}$, pallium; $\mathrm{pA}$, polyadenylation; $\mathrm{pt}$, pretectum; pth, prethalamus; po, pons; sc, spinal cord; sp, subpallium; tel, telencephalon; YAC, yeast artificial chromosome.

\section{Authors' contributions}

D. Tyas did most of the work towards generating the transgenic mouse, T.I. Simpson helped design and supervise the work, C.B. Carr did some of the expression analysis, D.A. Kleinjan collaborated on the generation of the mouse and V. van Heyningen, J.O. Mason and D.J. Price participated in design and supervision and in writing the manuscript.

\section{Acknowledgements}

We thank Linda Wilson for help with confocal microscopy, Clare Huxley for help with isolation of YAC DNA, Anne Seawright for help with FISH analysis, and Manchester University for injecting the oocytes with the YAC. Financial support was from an MRC Scholarship (DT), an Edinburgh College of Medicine Scholarship (CC), and from MRC, BBSRC and Wellcome Trust grants to JM and DP.

\section{References}

I. Walther C, Gruss P: Pax-6, a murine paired box gene, is expressed in the developing CNS. Development 1991, I 13:1435-1449

2. Grindley JC, Davidson DR, Hill RE: The role of Pax6 in eye and nasal development. Development 1995, 21 2: I433-1442.

3. St-Onge L, Sosa-Pineda B, Chowdhury K, Mansouri A, Gruss P: Pax6 is required for differentiation of glucagon-producing alphacells in mouse pancreas. Nature 1997, 387:406-409.

4. Hill RE, Favor J, Hogan BL, Ton CC, Saunders GF, Hanson IM, Prosser J, Jordan T, Hastie ND, van Heyningen V: Mouse small eye results from mutations in a paired-like homeobox-containing gene. Nature 199I, 354:522-525.

5. Hogan BL, Horsburgh G, Cohen J, Hetherington CM, Fisher G, Lyon MF: Small eyes (Sey): a homozygous lethal mutation on chromosome 2 which affects the differentiation of both lens and nasal placodes in the mouse. J Embryol Exp Morphol 1986, 97:95-II0.

6. Caric D, Gooday D, Hill RE, McConnell SK, Price DJ: Determination of the migratory capacity of embryonic cortical cells lacking the transcription factor Pax-6. Development 1997, I 24:5087-5096.

7. Mastick GS, Davis NM, Andrew GL, Easter SS Jr: Pax-6 functions in boundary formation and axon guidance in the embryonic mouse forebrain. Development 1997, 124:1985-1997.

8. Stoykova A, Fritsch R, Walther C, Gruss P: Forebrain patterning defects in Small eye mutant mice. Development 1996, I 22:3453-3465

9. Stoykova A, Gotz M, Gruss P, Price J: Pax6-dependent regulation of adhesive patterning, $R$-cadherin expression and boundary formation in developing forebrain. Development 1997, 1 24:3765-3777.

10. Warren N, Price DJ: Roles of Pax-6 in murine diencephalic development. Development 1997, 124:1573-1582.

II. Engelkamp D, Rashbass P, Seawright A, van Heyningen V: Role of Pax6 in development of the cerebellar system. Development 1999, I 26:3585-3596.

12. Warren N, Caric D, Pratt T, Clausen JA, Asavaritikrai P, Mason JO, Hill RE, Price DJ: The transcription factor, Pax6, is required for cell proliferation and differentiation in the developing cerebral cortex. Cereb Cortex 1999, 9:627-635.

13. Pratt T, Vitalis T, Warren N, Edgar JM, Mason JO, Price DJ: A role for Pax6 in the normal development of dorsal thalamus and its cortical connections. Development 2000, 127:5167-5I78.

14. Estivill-Torrus G, Vitalis T, Fernandez-Llebrez P, Price DJ: The transcription factor Pax6 is required for development of the diencephalic dorsal midline secretory radial glia that form the subcommissural organ. Mech Dev 200I, 109:2I5-224.

15. Sisodiya SM, Free SL, Williamson KA, Mitchell TH, Willis C, Stevens JM, Kendall BE, Shorvon SD, Hanson I, Moore AT, Van Heyningen V: PAX6 haploinsufficiency causes cerebral malformation and olfactory dysfunction in humans. Nature Genetics 200I, 28:2।4-216.

16. Ton CC, Hirvonen H, Miwa H, Weil MM, Monaghan P, Jordan T, van Heyningen V, Hastie ND, Meijers-Heijboer H, Drechsler M: Positional cloning and characterization of a paired box- and homeobox-containing gene from the aniridia region. Cell 1991, 67:1059-1074.

17. Schedl A, Ross A, Lee M, Engelkamp D, Rashbass P, van Heyningen $V$, Hastie ND: Influence of PAX6 gene dosage on development: overexpression causes severe eye abnormalities. Cell 1996, 86:7I-82.

18. Bishop KM, Goudreau G, O'Leary DD: Regulation of area identity in the mammalian neocortex by Emx2 and Pax6. Science 2000, 288:344-349.

19. Bishop KM, Rubenstein JL, O'Leary DD: Distinct actions of Emx I, Emx2, and Pax6 in regulating the specification of areas in the developing neocortex. J Neurosci 2002, 22:7627-7638.

20. Muzio L, DiBenedetto B, Stoykova A, Boncinelli E, Gruss P, Mallamaci A: Emx2 and Pax6 Control Regionalization of the Pre-neuronogenic Cortical Primordium. Cerebral Cortex 2002, I 2: 129-139.

21. Fantes J, Redeker B, Breen M, Boyle S, Brown J, Fletcher J, Jones S, Bickmore W, Fukushima Y, Mannens M: Aniridia-associated cytogenetic rearrangements suggest that a position effect may cause the mutant phenotype. Hum Mol Genet 1995, 4:415-422. 
22. Crolla JA, Cross I, Atkey N, Wright M, Oley CA: FISH studies in a patient with sporadic aniridia and t(7;II) (q3 I.2;pI3). J Med Genet 1996, 33:66-68.

23. Lauderdale JD, Wilensky JS, Oliver ER, Walton DS, Glaser T: 3' deletions cause aniridia by preventing PAX6 gene expression. Proc Natl Acad Sci USA 2000, 97: I 3755-I 3759.

24. Kleinjan DA, Seawright A, Schedl A, Quinlan RA, Danes S, van Heyningen V: Aniridia-associated translocations, DNase hypersensitivity, sequence comparison and transgenic analysis redefine the functional domain of PAX6. Hum Mol Genet 200I, 1 0:2049-2059.

25. Griffin C, Kleinjan DA, Doe B, van Heyningen V: New 3' elements control Pax6 expression in the developing pretectum, neural retina and olfactory region. Mech Dev 2002, I I 2:89- I00.

26. Kleinjan DA, Seawright A, Childs AJ, van Heyningen V: Conserved elements in Pax6 intron 7 involved in (auto)regulation and alternative transcription. Dev Biol 2004, 265:462-477.

27. Tyas D, Pratt T, Simpson TI, Mason JO, Price DJ: Identifying GFP transgenic mice by flashlight. Biotechniques 2003, 34:474-476.

28. Vitalis T, Cases O, Engelkamp D, Verney C, Price DJ: Defect of tyrosine hydroxylase-immunoreactive neurons in the brains of mice lacking the transcription factor Pax6. J Neurosci 2000, 20:650I-65I6.

29. Fernandez AS, Pieau C, Reperant J, Boncinelli E, Wassef M: Expression of the Emx-I and Dlx-I homeobox genes define three molecularly distinct domains in the telencephalon of mouse, chick, turtle and frog embryos: implications for the evolution of telencephalic subdivisions in amniotes. Development 1998 , I25:2099-III.

30. Heins N, Malatesta P, Cecconi F, Nakafuku M, Tucker KL, Hack MA, Chapouton P, Barde YA, Gotz M: Glial cells generate neurons: the role of the transcription factor Pax6. Nat Neurosci 2000 5:308-3I5

31. Kim J, Lauderdale JD: Analysis of Pax6 expression using a BAC transgene reveals the presence of a paired-less isoform of Pax6 in the eye and olfactory bulb. Dev Biol 2006 in press.

32. Hamer L, Johnston M, Green ED: Isolation of yeast artificial chromosomes free of endogenous yeast chromosomes: construction of alternate hosts with defined karyotypic alterations. Proc Natl Acad Sci USA 1995, 92: I I706-10.

33. Vollrath D, Davis RW, Connelly C, Hieter P: Physical mapping of large DNA by chromosome fragmentation. Proc Natl Acad Sci USA 1 988, 85:6027-3I.

34. Spencer F, Hugerat Y, Simchen G, Hurko O, Connelly C, Hieter P: Yeast kar I mutants provide an effective method for YAC transfer to new hosts. Genomics 1994, 22: I I 8-26.

35. Hugerat $Y$, Spencer F, Zenvirth D, Simchen G: A versatile method for efficient YAC transfer between any two strains. Genomics 1994, 22:108-17.

36. Vagner S, Galy B, Pyronnet S: Irresistible IRES. Attracting the translation machinery to internal ribosome entry sites. EMBO Rep 2001, 2:893-898.

37. Yonaha M, Proudfoot NJ: Transcriptional termination and coupled polyadenylation in vitro. EMBO J 2000, 19:3770-3777.

38. Soderholm J, Bevis BJ, Glick BS: Vector for pop-in/pop-out gene replacement in Pichia pastoris. Biotechniques 200I, 3 I:306-I0.

39. Boeke JD, Trueheart J, Natsoulis G, Fink GR: 5-Fluoroorotic acid as a selective agent in yeast molecular genetics. Methods Enzymol 1987, I 54: 164-75.

40. Chu G, Vollrath D, Davis RW: Separation of large DNA molecules by contour-clamped homogeneous electric fields. Science 1986, 234: 1582-5.

41. Brudno M, Do C, Cooper G, Kim MF, Davydov E, Green ED, Sidow A, Batzoglou S: LAGAN and Multi-LAGAN: efficient tools for large-scale multiple alignment of genomic DNA. Genome Research 2003, | 3:721-31.

42. Mayor C, Brudno M, Schwartz JR, Poliakov A, Rubin EM, Frazer KA Pachter LS, Dubchak I: VISTA: Visualizing Global DNA Sequence Alignments of Arbitrary Length. Bioinformatics 2000, 16:1046.

43. Loots G, Ovcharenko I, Pachter L, Dubchak I, Rubin E: rVISTA for comparative sequence-based discovery of functional transcription factor binding sites. Genome Res 2002, 12:832-839.
Publish with Biomed Central and every scientist can read your work free of charge

"BioMed Central will be the most significant development for disseminating the results of biomedical research in our lifetime. "

Sir Paul Nurse, Cancer Research UK

Your research papers will be:

- available free of charge to the entire biomedical community

- peer reviewed and published immediately upon acceptance

- cited in PubMed and archived on PubMed Central

- yours - you keep the copyright

Submit your manuscript here:

http://www.biomedcentral.com/info/publishing_adv.asp 